\title{
Nouveau plan de formation pour les assistantes médicales CFC
}

\section{Carlos Beat Quinto}

Dr méd., responsable du département Santé publique et professions de la santé

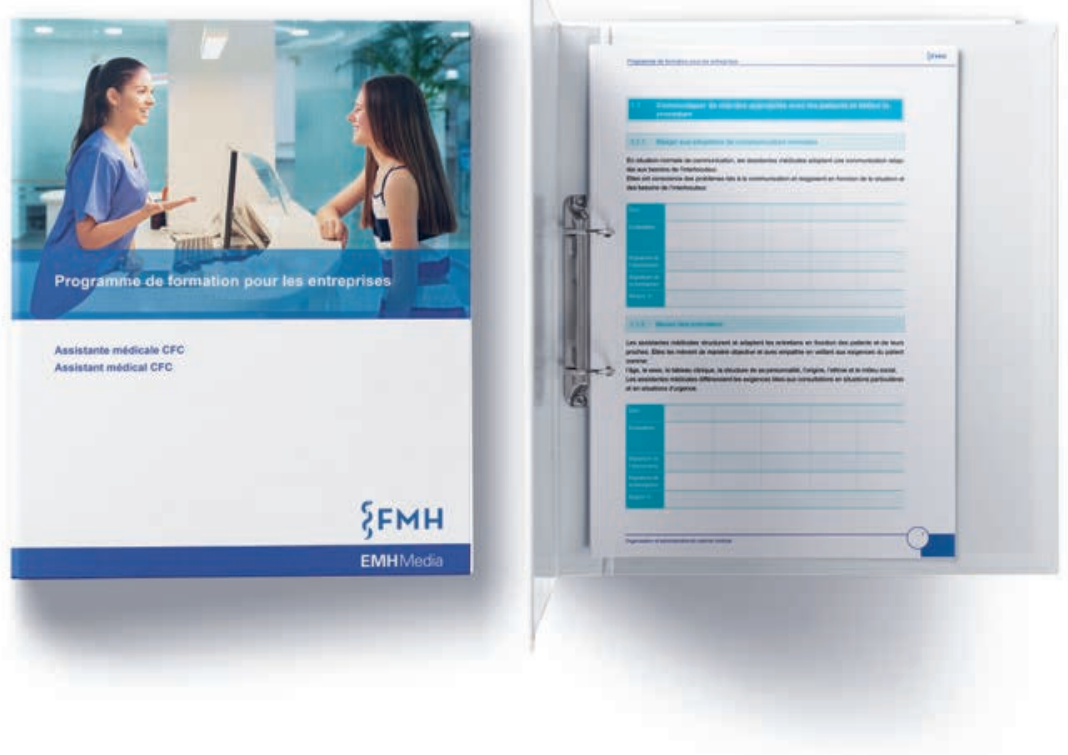

\author{
Programme de formation pour les entreprises \\ (cabinet médical) \\ Assistante médicale / Assistant médical CFC
}

FMH Fédération des médecins suisses (editeur) Basel: EMH Editions médicales suisses SA; 2019.

\section{La version imprimée non reliée est disponible au prix de 32 francs/pièce.}

Version imprimée en français: ISBN 978-3-03754-127-2 Version imprimée en allemand: ISBN 978-3-03754-126-5 Version imprimée en italien: ISBN 978-3-03754-128-9

\section{La version électronique est disponible au prix} de 20 francs/pièce.

Version électronique en français: ISBN 978-3-03754-130-2 Version électronique en allemand: ISBN 978-3-03754-129-6 Version électronique en italien: ISBN 978-3-03754-131-9
L'ordonnance sur la formation (orfo) et le plan de formation des assistantes médicales avec certificat fédéral de capacité ( $\mathrm{CFC}$ ) sont réexaminés tous les cinq ans et révisés, si nécessaire. La dernière révision, étendue sur plusieurs années, a été mise en vigueur au $1^{\text {er }}$ janvier 2019 par le Secrétariat d'Etat à la formation, à la recherche et à l'innovation (SEFRI).

La première volée d'assistantes médicales formées selon l'orfo et le plan de formation révisés débutera sa formation en août 2019.

Le support d'enseignement «Programme de formation pour les entreprises» a été élaboré suite à la révision de l'orfo. Comme la médecine se caractérise par une évolution constante du niveau de connaissance, il s'est avéré indispensable de renouveler les contenus enseignés et de revoir leur pondération. De plus, les personnes qui suivent une formation d'assistante médicale CFC peuvent désormais aussi, si elles le souhaitent, se présenter aux examens de maturité professionnelle parallèlement à leur activité. Il s'agit, d'une part, d'une exigence du SEFRI qui permet, d'autre part, d'accroître l'attractivité de la formation d'assistante médicale. L'objectif est de susciter l'intérêt des personnes suffi- samment qualifiées pour une formation qui débouche sur une activité professionnelle polyvalente et exigeante.

Très variée, la profession d'assistante médicale inclut plusieurs champs d'activité. La formation vise donc à enseigner de nombreuses compétences mais aussi à les approfondir et à les mettre en pratique. Le support d'enseignement «Programme de formation pour les entreprises» a été élaboré aussi bien à l'intention des personnes en formation que des formateurs et leur permet, de manière simple, d'avoir une vue d'ensemble permanente des compétences requises et des différentes étapes. Ce support d'enseignement a donc également été créé pour être un outil de travail, comme le préconise les exigences didactiques actuelles. Juste à temps pour la rentrée scolaire, le «Programme de formation pour les entreprises» est disponible en version imprimée ou électronique dans les trois langues nationales.

La formation des assistantes médicales sera, à partir de la rentrée 2019, axée sur les compétences opérationnelles. On ne parle désormais plus de branches. 
Nous aimerions attirer votre attention sur la parution d'un autre support d'enseignement: le «Plan d'études pour les écoles professionnelles et programme de formation en cours interentreprises». Ce plan d'études vise principalement à mettre en relation les lieux d'apprentissage. Il est donc important que les responsables de la formation dans les entreprises le consultent. Les connaissances théoriques et les compétences pratiques sont enseignées sur trois types de sites différents: l'école professionnelle, l'entreprise for- matrice et les cours interentreprises, organisés par les sociétés cantonales de médecine, en collaboration (au choix) avec d'autres organismes. Entretemps, certains cantons/régions ont mis sur pied des "conférences de coordination des lieux d'apprentissage» auxquelles nous recommandons vivement à tous les responsables de la formation de participer. En règle générale, ces conférences sont organisées par les offices cantonaux de la formation professionnelle.

Plan d'études pour les écoles professionnelles et programme de formation en cours interentreprises Assistante médicale / Assistant médical avec certificat fédéral de capacité (CFC)

FMH Fédération des médecins suisses (editeur) Basel: EMH Editions médicales suisses SA; 2019.

La version imprimée est disponible au prix de 49 francs/pièce.

Version imprimée en français: ISBN 978-3-03754-125-8

Version imprimée en allemand: ISBN 978-3-03754-124-1

La version électronique est disponible au prix de 35 francs/pièce.

Version électronique en allemand: ISBN 978-3-03754-132-6 Version électronique en français: ISBN 978-3-03754-133-3

Veuillez adresser vos commandes du «Programme de formation pour les entreprises» et du «Plan d'études pour les écoles professionnelles et programme de formation en cours interentreprises» à: EMH, Editions médicales suisses, Bâle: auslieferung[at]emh.ch Vous trouverez de plus amples informations concernant la formation des assistantes médicales CFC ou les employeurs sur le site internet www.am-suisse.ch 